\title{
Research on Economic Growth and Information Exchange Based on B2B E-commerce
}

\author{
Wen Chunling*
}

School of Business, Changzhou University, Changzhou, China

\begin{abstract}
This paper studies the relationship between B2B e-commerce transaction volume and GDP by using cointegration relation test and Engel-Granger test methods. The result shows that long-term stable co-integration relationship did not exist: B2B causes the growth of GDP, but GDP is not the reason for the increase in B2B transactions. Meanwhile, this article also aimed to study the influence of $\mathrm{B} 2 \mathrm{~B}$ e-commerce information retrieval and communication, and extracted different B2B e-commerce mode of information retrieval and communication mode to improve the efficiency of information retrieval and communication, making the business flow, logistics, and cash flow more smooth.
\end{abstract}

Keywords: B2B, communication, e-commerce, GDP, information retrieval.

\section{INTRODUCTION}

$\mathrm{B} 2 \mathrm{~B}$ i.e. Business to Business, and $\mathrm{B} 2 \mathrm{~B}$ e-commerce refer to the electronic business activities such as exchange of products services and information between enterprises through the Internet [1].

In 2011, China's volume of B2B transaction was 4.9 trillion yuan, and in 2012, the deal size was expected to reach 7.5 trillion yuan. At present, e-commerce has been gradually penetrated into all aspects of economy and society. With a number of factors [2], driven by China's B2B, ecommerce development will witness a blowout, highlighting the relationship between $\mathrm{B} 2 \mathrm{~B}$ electronic commerce and economic development.

Firstly, dissertation analysed the factors of electronic commerce impacting on Economic growth and costeffective identification method in E-commerce transaction. But there is a difference in different stages. In accordance with the economic theory of E-commerce, cost-effective identification in E-commerce transaction is different from that of investment projects in traditional technical economics. The value of their products and services is fixed. The accounting research on the E-commerce transaction cost-effectiveness requires aid from traditional finance theory and E-commerce economic theory [3].

Secondly, the dissertation studied the interaction between the growth of electronic commerce and economic development, and plotted a development trend curve. Following this, the dissertation puts forward the view not to develop E-commerce and e-business in the beginning of industrialization, pointing to the trend curve of interaction

*Address correspondence to this author at the Changzhou University, Changzhou, China; Tel: +86-186-5199-3500; Fax: +86-186-5199-3500; E-mail: iemail2011@qq.com between E-commerce and economic growth. A mutual interaction exists was observed having mutual promotion and constraints between E-commerce and economic growth. The changing regulation presented a " $U$ " type trend.

\section{ECONOMIC GROWTH AND B2B E-COMMERCE}

The overall volume of $\mathrm{B} 2 \mathrm{~B}$ transactions is much higher than the volume of $\mathrm{B} 2 \mathrm{C}$ transactions. The primary reason for this is that in a typical supply chain, there will be many B2B transactions involving sub components or raw materials, and only one B2C transaction, specifically sale of the finished product to the end customer. For example, an automobile manufacturer makes several B2B transactions such as buying tires, glass for windscreens, and rubber hoses for its vehicles. While in the final transaction, a finished vehicle sold to the consumer, is a single (B2C) transaction $[4,5]$.

$\mathrm{B} 2 \mathrm{~B}$ is also used in the context of communication and collaboration. Many businesses are now using social media to connect with their consumers (B2C); however, they now use similar tools within the business so that employees can connect with one another. When communication takes place amongst employees, this can be referred to as "B2B" communication [6].

Table 1 shows the data of China's B2B e-commerce transactions and gross domestic product (GDP) in 20002011. B2B e-commerce transactions emerged in 1990s in China. After more than ten years of development, B2B trade had already begun to take shape, from 76.8 billion in 2000 to 4.9 trillion in 2011 , nearly 64 times ; B2B transactions as a share of GDP increased from $0.77 \%$ in 2000 to $10.39 \%$ in 2011 (Fig. 1). With the improvement in e-commerce trading environment and the development of the virtual economy, the development scale of B2B e-commerce transactions will be larger, and its share in the GDP will be higher . 
Table 1. B2B e-commerce transactions and GDP.

\begin{tabular}{|c|c|c|}
\hline Year & $\begin{array}{c}\text { B2B E-Commerce } \\
\text { Transactions (Billion Yuan) }\end{array}$ & $\begin{array}{c}\text { GDP } \\
\text { (Billion Yuan) }\end{array}$ \\
\hline 2000 & 768 & 109655 \\
\hline 2001 & 1075 & 120333 \\
\hline 2002 & 1250 & 135823 \\
\hline 2003 & 1390 & 159878 \\
\hline 2004 & 3160 & 183085 \\
\hline 2005 & 6500 & 183085 \\
\hline 2006 & 12800 & 216314 \\
\hline 2007 & 15317 & 265813 \\
\hline 2008 & 21480 & 314045 \\
\hline 2009 & 25000 & 340507 \\
\hline 2010 & 38000 & 397983 \\
\hline 2011 & 49000 & 471564 \\
\hline
\end{tabular}

\section{B2B E-COMMERCE TRANSACTIONS AND GDP CORRELATION ANALYSIS}

In this study, with the help of econometrics and time series method, relationship of B2B trading with economy for empirical was analysed empirically.

The study used ADF to test B2B e-commerce transactions and GDP in 2000-2011. Suppose Y stands for B2B transactions (Y) and GDP(x), the following three model of unit root test sequence can be used:

$$
\begin{aligned}
& \Delta Y t=\omega Y_{t-1}+\sum_{i=1}^{k} \beta_{i} \Delta Y_{t-i}+\varepsilon_{t} \\
& \Delta Y_{t}=\alpha+\omega Y_{t-1}+\sum_{i=1}^{k} \beta_{i} \Delta Y_{t-i}+\varepsilon_{t} \\
& \Delta Y_{t}=\alpha+\omega Y_{t-1}+\sum_{i=1}^{k} \beta_{i} \Delta Y_{t-i}+\varepsilon_{t} \\
& \ln _{y}=\alpha+\beta x+\mu
\end{aligned}
$$

\section{Among them: $\varepsilon \sim\left(0, \sigma^{2}\right)$}

Model (1) was used to test sequence without intercept and trend; Model (2) was used to test sequence with intercept item but without trend; Model (3) tested the sequence with both intercept and trend. Before testing GDP (x) and B2B e-commerce transactions (y) with ADF inspection, one should first observe the sequence diagram (see Fig. 2).

Fig. (2) shows that the $\mathrm{x}$ and $\mathrm{y}$ had a rising trend and intercept, therefore, model (3) was used to test sequence. ADF test results are shown in Table 2.

The results show that the two variables of ADF T statistic values were greater than the critical value with $5 \%$ significant level, therefore null hypothesis was accepted. These two variables represent the unit root, and were not stable.

In 2014, according to the CNNIC: the $33^{\text {rd }}$ China's Internet network development state statistics report is shown in Fig. (3). In December 2013, there were 618 million Internet users in China, and a total of 53.58 million Internet users were further estimated throughout the year. Internet penetration rate was $45.8 \%$, a $3.7 \%$ increase compared with

Figure1:B2B e-commerce transactions'proportion in GDP

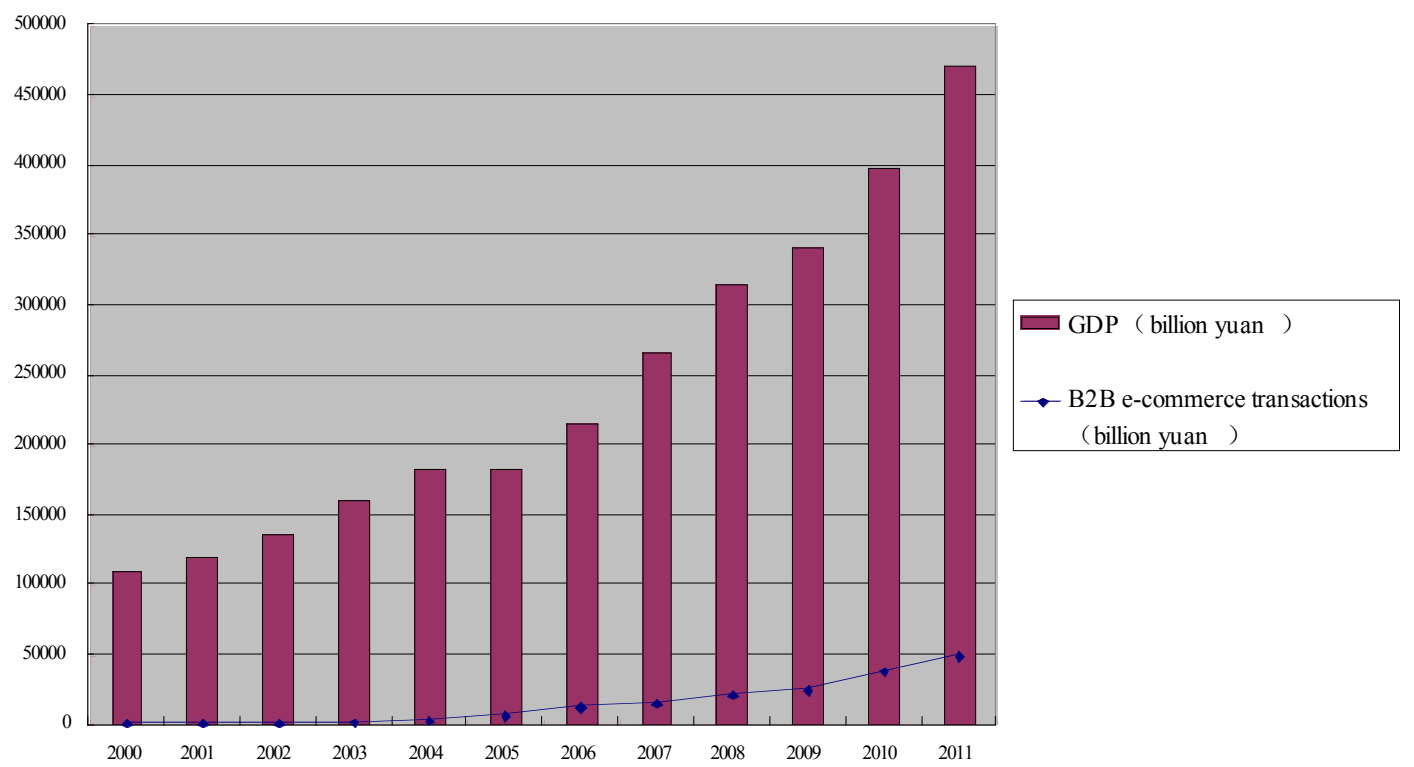

Fig. (1). B2B e-commerce transactions ‘ proportion in GDP. 

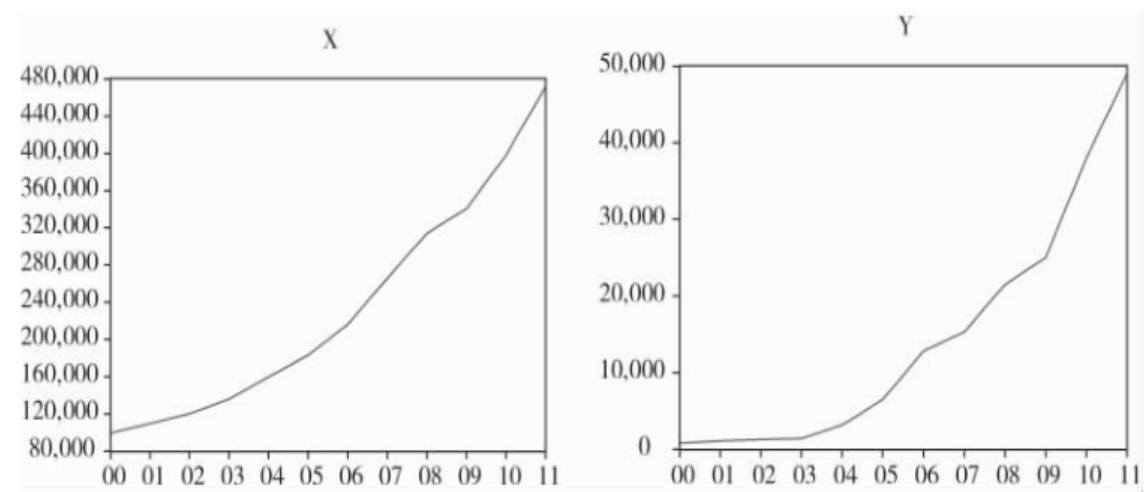

Fig. (2). B2B e-commerce transactions'proportion in GDP.

Table 2. ADF test of $x$ and $y$ values TAB.

\begin{tabular}{|c|c|c|c|}
\hline & DW & ADF T Statistics & 5\% Critical Value \\
\hline \hline GDP (x) & 2.16 & $-1,02$ & -4.11 \\
\hline B2B transactions (y) & 2.81 & 0.53 & -3.93 \\
\hline
\end{tabular}

2012. There were 500 million mobile phone Internet users, highlighting an increase of 80.09 million compared with the end of 2012. Cellphone netizens account increased by $81.0 \%$ in the whole Internet users. Internet penetration is steadily increased, but compared with the developed countries, Internet penetration in China is still at a very low level. Therefore, according to the present development in the use of Internet in our country, the future of our country electronic commerce has broad prospects for development.

\section{THE INFLUENCE FACTORS OF E-COMMERCE BENEFITS}

Due to the different level of economic growth, the electronic commerce development has shown different effect on economic growth, therefore different stages of the electronic commerce cause different changes.
There are some major factors affecting the initial stage of e-commerce development in China.

In general, at the initial stage of e-commerce development, factors like enterprise information flow, capital and cash-flow directly affect the level of electronic commerce technology development and the balance of supply and demand in market application. However, the core elements in the development of e-commerce applications are in demand [7].

In addition, there are some factors affecting the takeoff stage of e-commerce development in China.

E-commerce, from the beginning, entered the stage of development, with positive contribution to economic growth. At this time, the major influence factors are internal

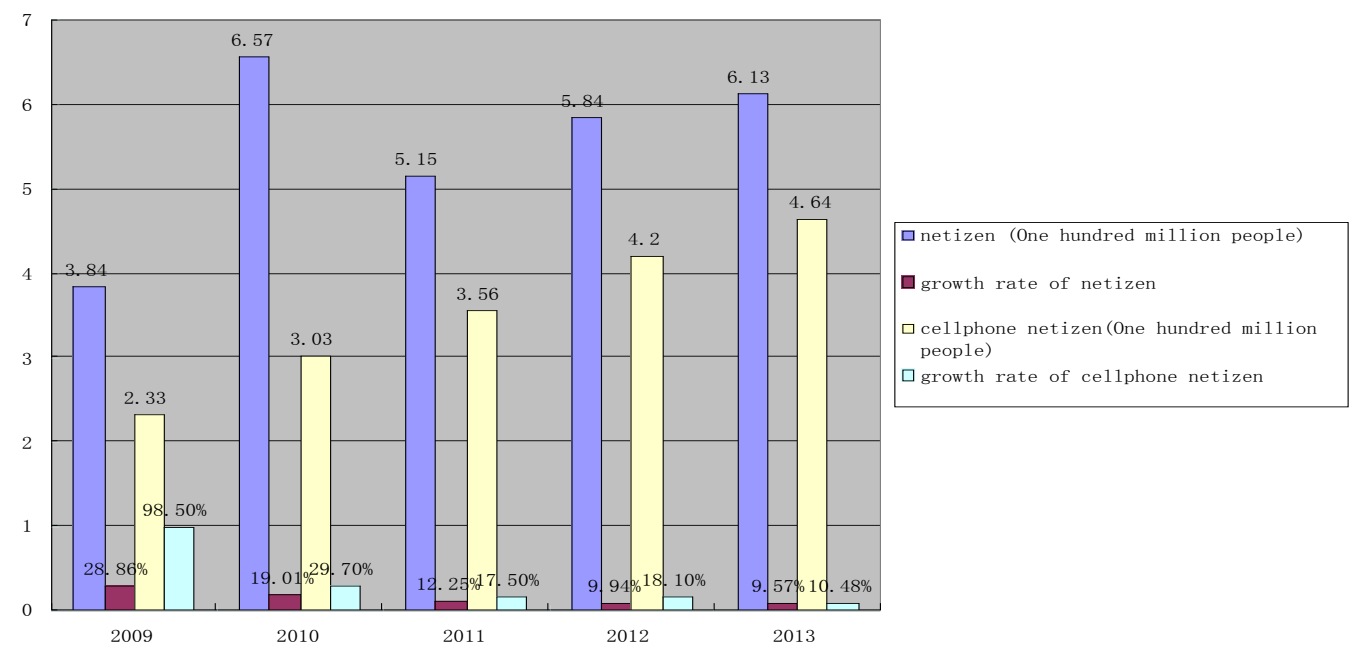

Fig. (3). China's total netizens and cellphone netizens (0.1billion people) and its rate of growth in 2000-2011. 
Table 3. The basic factors for the economic growth of E-commerce.

\begin{tabular}{|c|c|c|}
\hline & Influence Factors & \\
\hline & Core factors & $\begin{array}{l}\text { Information flow demand } \\
\text { Capital flow demand } \\
\text { Logistics demand }\end{array}$ \\
\hline $\begin{array}{c}\text { The influence factors of e-commerce } \\
\text { development in early stage }\end{array}$ & 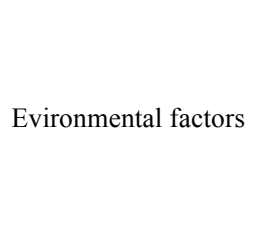 & $\begin{array}{l}\text { The international competitive environment } \\
\text { Social policy and law } \\
\text { The market economy environment } \\
\text { Political and cultural environment } \\
\text { Business environment }\end{array}$ \\
\hline
\end{tabular}

Table 4. The determinants of e-commerce contribution to economic growth.

\begin{tabular}{|c|c|c|}
\hline \multirow[t]{2}{*}{ Determinants of e-commerce growth } & Internal factors & $\begin{array}{c}\text { Enterprise technology progress } \\
\text { Electronic financial } \\
\text { The enterprise information development } \\
\text { Network infrastructure } \\
\text { Talent development environment } \\
\text { Organization structure and efficiency }\end{array}$ \\
\hline & External factors & $\begin{array}{l}\text { The international competitive environment } \\
\text { Social policy and law } \\
\text { The market economy environment } \\
\text { Political and cultural environment } \\
\text { Business environment }\end{array}$ \\
\hline
\end{tabular}

elements of e-commerce system; meanwhile, factors outside the country's economic system are also very important [8].

To sum up, the development in electronic commerce for many years, and in many countries, including China, has entered the take-off stage. According to practical experience, the development of e-commerce market, talent, technology, finance, international and institutional environment are the important influencing factors as mentioned in Table 3 .

\section{INFORMATION RETRIEVAL AND COMMUNI- CATION AND B2B E-COMMERCE}

information retrieval and communication hold immense importance in a countrys' economic development.

Because of the lack of information sharing, production and demand are not symmetric, thus causing shortage and excess of products at the same time.

Because the buyers are limited, many buyers and sellers form multi-level sales chain, making a lot of intermediate links, therefore the cost of sales becomes higher; Because of the limitation of buyers and sellers, buying and selling bids are inadequate, which effects transaction efficiency and does not help to create a fair market environment;

\section{Analysis of information retrieval and communication in online business}

Information reflects recent changes and features in the objective world. Information is reflected through certain forms of material carrier, and is the state of substance, the form and law of movement.(AUTHOR: Clarigy the highlighted text) Therefore, the concept of network business information can be defined from the above definition of business information and network information: it refers to the information that can reflect various features in operational activities, precisely and timely, by means of digital network a, storage, transmission and management. (AUTHOR: Review the highlighted text). Business information plays a determinant role in the discovery of business opportunities [9].

Due to increased information sources, access to information is easy and online information has also increased exponentially. At present, the number of databases that only connect to the Internet is tens of thousands, other information is more difficult to calculate. There are a variety 
of forms of information including, network publications, dynamic information, all kinds of databases, software resources and other information. In addition, information is stored in different formats including; text, images, audio and video information and each includes a variety of file access formats. The Internet itself is an institution without special management. Free connection, free release information, free extension, widely used service mode and free service content are the biggest characteristics of Internet. Therefore, through network, information resources are distributed, with no fixed order, and without a unified system and structure [10].

\section{CONCLUSION}

In today's competitive business environment, companies seek ways to perform transactions efficiently and effectively. The Internet has created a flexible platform for the buying and selling of products and services. Internet is an open global network with heterogeneous, dynamic, interoperability and other features. Every site on the Internet is a Data Source. The types of information and ways of organization are different from site to site. And these sites form a huge heterogeneous information resource environment that contains structured, semi- structured and unstructured Information resources. Information has its value. Through useful information, one can eliminate the uncertainty of economic decision-making, reduce the cost of economic behavior, increase the proceeds of economic behavior, and thus enhance economic efficiency.

\section{CONFLICT OF INTEREST}

The author confirms that this article content has no conflicts of interest.

\section{REFERENCES}

[1] A.M. Fairchild and R.R. Peterson, "Business-to-business value drivers and e-business infrastructures in financial services: collaborative commerce across global markets and networks", System Sciences, vol. 8, pp: 1-5, 2008.

[2] C.-H. Wang, R.-I. Chang, J.-M. Ho, "An effective communication model for collaborative commerce of web-based surveillance services", E-Commerce, vol. 7, pp: 1-8, 2013.

[3] C. Chan, M. Paula and C. Swatman, "Management and business issues for B2B e-Commerce implementation", Proceedings of the 35th Hawaii International Conference on System Sciences, vol. 10, pp: 126-129, 2012.

[4] D. Boughaci and H. Drias, "An Agent-based spproach using the ebXML specifications for E-business. information technology" Coding and Computing, vol. 7, pp: 259-263, 2009.

[5] K. Zhu, "Economic Implications of B2B Electronic Markets: The Private and Social Desirability of Information Transparency", Proceedings of the 37th Hawaii International Conference on System Sciences, vol. 8, pp: 23-28, 2014.

[6] K. Fuks and W. Wieczerzycki, "A new approach to information exchange within Public Registries based on RosettaNet standards", Database and Expert Systems Applications, vol. 7, pp: 1132-1136, 2006.

[7] L.L. Sowinski, "Is there a perfect logistics software product on the market", World Trade, vol. 13, no. 2, pp:32-36, 2010.

[8] Simon S.Y.Shim, Vishnu S.Pendyala, Meera Sundaram, Businessto-Business E-Commerce Frameworks. Computer, 2010, (10) pp: 40-46.

[9] W.Y. Zhang, "Research of web-based negotiation support system in collaborative commerce", e-Business Engineering, vol. 5, pp: 1121-1125, 2010.

[10] K. Zhu, "Information transparency in electronic marketplaces: Why data transparency may hinder the adoption of B2B exchanges", B2B E-Commerce, vol. 2, pp: 92-99, 2012. 